\title{
Abattoir Based Study on the Pathology of Tuberculosis in Dromedary Camels, Ethiopia
}

\author{
Yasmin Jibril ${ }^{1 *}$, Gezahegne Mamo ${ }^{2}$, Jemal Ahmed ${ }^{1}$, Gete Mulat ${ }^{1}$ and Gobena Ameni ${ }^{3}$ \\ ${ }^{1}$ Department of Clinical Studies, Ethiopia \\ ${ }^{2}$ Department of Microbiology, Ethiopia \\ ${ }^{3}$ Aklilu Lemma Institute of Pa tho-Biology, Ethiopia
}

*Corresponding author: Yasmin Jibril, Department of Clinical Studies, Ethiopia

\begin{abstract}
ARTICLE INFO
Received: 蔧 June 17, 2019

Published: 彗 June 26, 2019

Citation: Yasmin J, Gezahegne M, Jemal A, Gete M, Gobena A. Abattoir Based Study on the Pathology of Tuberculosis in Dromedary Camels, Ethiopia. Biomed J Sci \& Tech Res 19(2)-2019. BJSTR. MS.ID.003263.
\end{abstract}

Keywords: Akaki Abattoir; Central Ethiopia; Dromedary Camels; Epidemiology; Gross Pathology; Tuberculosis

\section{ABSTRACT}

Background: Camels are important sources of milk and meat for the pastoral communities of East Africa as they are adapted to the harsh environment in this region. However, these animals are facing different health constraints including tuberculosis (TB). TB can also be transmitted to pastoralists from camels since their milk is consumed raw and as the pastoralists live in close physical contact with potentially infected camels. However, little data is available on the epidemiology of TB in camels in this region.

Methods: This study was undertaken from February, 2014 to July, 2016 to investigate pathological lesions of tuberculosis in camels slaughtered at Akaki abattoir, central Ethiopia. In order to achieve this objective, a cross-sectional study design was used to recruit 2070 camels for pathological investigation.

Results: The lesion prevalence of TB in camels slaughtered at Akaki Abattoir was 7.54\% (95\%CI: $6.45 \%-8.7 \%)$. Statistically significant association $(\chi 2=26.2, p=0.000)$ was observed between body condition of the camels and prevalence of TB. Multivariate logistic regression analysis revealed that poor body condition was significantly associated [p= 0.000, (Adjusted OR=2.55, 95\%CI: $1.743-3.734$ )] as a risk factor for TB in camels. Relatively higher frequency of lesion was detected in female, poor body conditioned, and Borena camels with a proportion of $87.2 \%, 46.2 \%$, and $84 \%$, respectively. Anatomically, lesion was frequently found in sub-mandibular (54.8\%) and retro-pharyngeal (16.94\%) lymph nodes. Moreover, severe lesion was observed in sub-mandibular $(2.47 \pm 0.24)$, retro-pharyngeal $(0.35 \pm 0.2)$ and trachea-bronchial $(0.35 \pm 0.2)$ lymph nodes.

Conclusion: The present study revealed that the detection of extensive tuberculosis lesions in camels could help to elucidate tuberculosis evidently prevalent in camels. However, the current pathological findings are not conclusive. Therefore, further cultural isolation and molecular characterization of strains causing tuberculosis in camels was recommended.

\section{Background}

In Eastern Africa, Ethiopia has the largest pastoralist population (7-8 millions) representing around 20 ethnic groups [1]. Pastoralists depend on livestock for their livelihood, moving seasonally from place to place in search of water and pasture for their animals [2]. In these communities, animal products such as milk consumed raw and this habit combined with close physical contact and sharing the same dwelling with their animals create a potential public health concern for transmission of zoonotic diseases such as tuberculosis (TB). The dromedary camels have an estimated world population of 18 million across the arid and semi-arid environments of African and Asian countries. In Africa, dromedary population of about 15 million accounts for about $74 \%$ of the world and of these, $60 \%$ are found in East African countries (Somalia, 6.2 million; Sudan, 2.8 million; Ethiopia, 1.7 million; Kenya, 0.9million) [3]. The threat posed by increasing and prolonged periods of drought particularly in arid and semi-arid areas of Africa has forced pastoralists to undergo adaptive strategies such as herd diversification, where emphasis on camel husbandry is becoming a priority. 
Increasing numbers of pastoralists in Ethiopia are herding camels in response to less predictable weather patterns, because camels are more drought hardy than any other species of animals. Tuberculosis affects Old World Camelids (OWC) including Dromedaries and Bacterian camles [4-7]. Tuberculosis is prevalent in camels; [8] indicated a higher TB prevalence of $13 \%$ in camels in Kazakistan and a more recent study in Ethiopian abattoirs indicated a similar prevalence of $10 \%$ based on the identification of gross lesions in apparently healthy dromedaries [9]. Camel TB has been described also in Pakistan [10], Nigeria [11] and Ethiopia [12-16,]. There is little published information on the epidemiology of TB specifically relating to camelids [3]. However, recently few studies have been conducted on the epidemiology of tuberculosis in dromedary camels in Ethiopia [12-16]. The objective of this study is therefore, to estimate the prevalence of TB in camels slaughtered at Akaki municipality abattoir using gross post mortem lesion.

\section{Materials and Methods}

\section{Study Area}

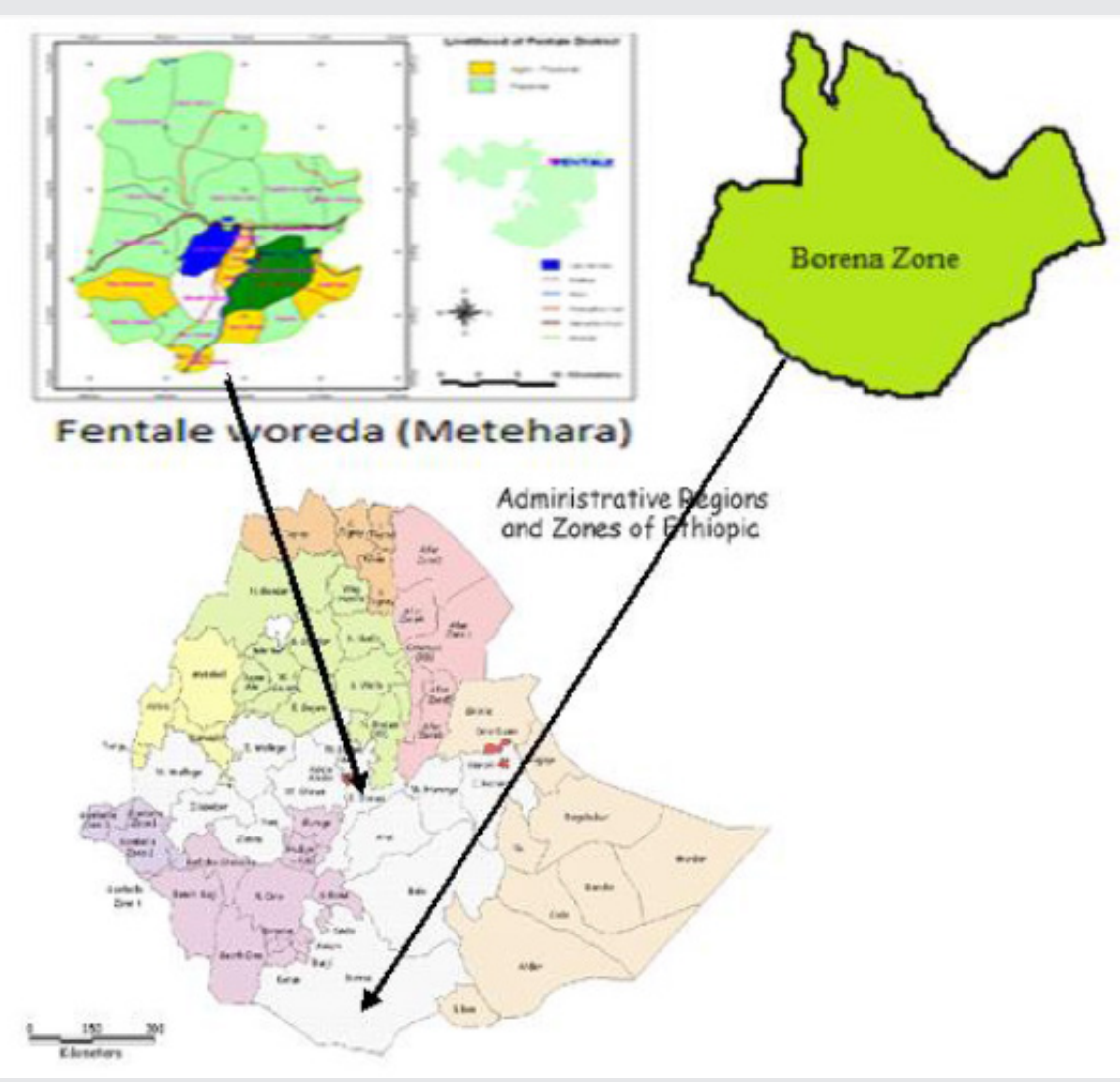

Figure 1: Map of Ethiopia with zones, showing the origin of camels (Borena and Methara).

This study was conducted from February, 2014 to July, 2016 to investigate the pathology of tuberculosis lesions in camels slaughtered at Akaki municipality abattoir, Central Ethiopia. The abattoir is located at Akaki town which is one of the sub-cities of Addis Ababa, the capital city. The camels slaughtered at the Akaki abattoir were originating mainly from the catchment (source) areas namely Borena and Fentale (Metehara) pastoral livestock production systems of Ethiopia (Figure 1). The main catchment areas possess large number of camels, in Fentale pastoral area, there are 61,425 camels and in Borena pastoral areas possess an estimated population of 174,185 camels $[6,17]$.

\section{Study Population}

The study camels were of Borena and Metehara (Fentale) origin from the catchment sites of Borena and Fentale pastoral livestock production systems of Oromiya regional state. On arrival, the camels will stay for few days in the holding pen until they are slaughtered.
On average, about 5 to 8 camels were slaughtered on daily bases during the study period depending on the consumer demand of Somali residents at Addis Ababa Bole Bulbula. For pathological investigation of gross visible tubercle lesions during post mortem examination, a total of 2070 camels considered during the study period. Camels were carefully identified: age, sex, origin and body condition score (BCS) were recorded. Body condition score was determined by hump structure of the camels according to the previously established guideline indicated in the website [18] and the scores ranges from 1 to 5 based on the amount of fat in the hump and then categorized into three groups: poor, moderate and good. Age category was determined by using the dental eruption and wears as described by [19]; accordingly, camels were categorized as adult ( $\leq 7$ years of age) and older camels ( $>7$ years of age). During the investigation, most camels were with poor body condition, old aged and with extensive branding (Figure 2). 


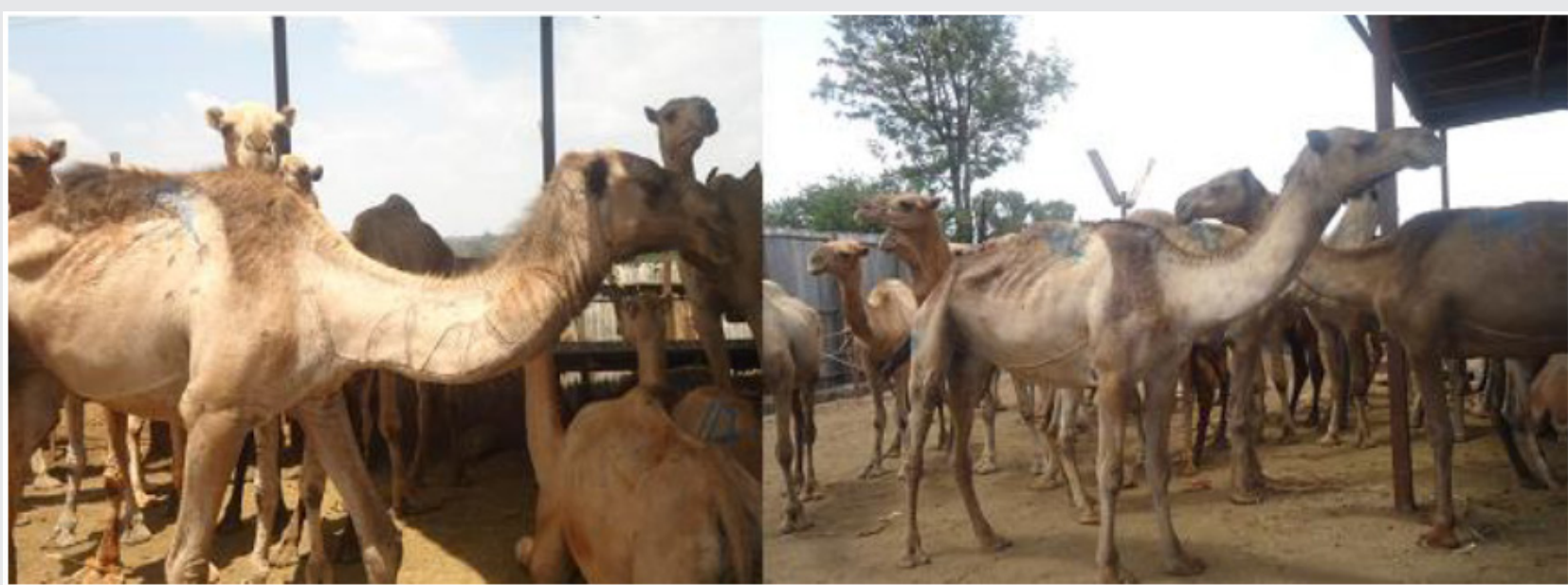

Figure 2: Old aged camels, poor body conditioned and with extensive branding.

\section{Study Design and Sampling}

Abattoir based cross sectional study design was employed to investigate tuberculosis lesions in apparently healthy camels slaughtered at Akaki municipality abattoir. Camels which were slaughtered on daily bases were followed during postmortem examination to investigate for the presence of any visible tubercle lesion from the lymph nodes of the head, lung tissue, and lung associated lymph nodes and also for pathology scoring of the lesions.

\section{Sample Size Determination}

To estimate the prevalence of tuberculosis in camels using gross pathological lesions, the formula for random sampling of [20] were employed. For this, 95\% confidence level, 5\% desired absolute precision, and expected prevalence of $10 \%$ [9] was considered.

$$
n=\frac{\text { üüü }^{2} p_{\exp }-P_{\exp }}{d^{2}}
$$

Where: $\mathrm{n}=$ required sample size, $\mathrm{P}_{\exp }=$ expected prevalence of $10 \%$

$\mathrm{d} 2=$ desired absolute precision of $5 \%, 1.96=\mathrm{Z}$ value of the $95 \%$ confidence level
To increase the precision of sample estimate as it is abattoir based epidemiological study, the sample size was increased and thus, a total, 2070 camels were investigated during the study period.

\section{Gross Pathology, Pathology Scoring and Tissue Sample Collection}

Postmortem examination was performed following the procedure as previously described $[9,21]$. Tissues from the lung, lymph nodes such as sub-mandibular lymph node, retropharyngeal lymph node, trachea-bronchial lymph node, cranial and caudal mediastinal lymph node were examined in detail under a brightlight source. The lobes of the left and right lungs were inspected and palpated externally. Then, each lobe is sectioned into about $2 \mathrm{~cm}$ thick slices to facilitate the detection of lesions with sterile surgical blades. Similarly, lymph nodes were sliced into thin sections (about $2 \mathrm{~mm}$ thick) and inspected for the presence of visible lesions. The cut surface was examined under a bright light source for the presence of abscess and tubercle lesions [9,22]. Camels with macroscopic lesions varying from firm or hard white, grey, or yellow nodule with a yellow, caseous, necrotic centre that was dry and solid to thin walled suppurative abscesses were classified as post mortem positive [23]. Whenever gross lesions suggestive of TB were detected in any of the tissues, the tissues were classified as having lesions (Figure 3).

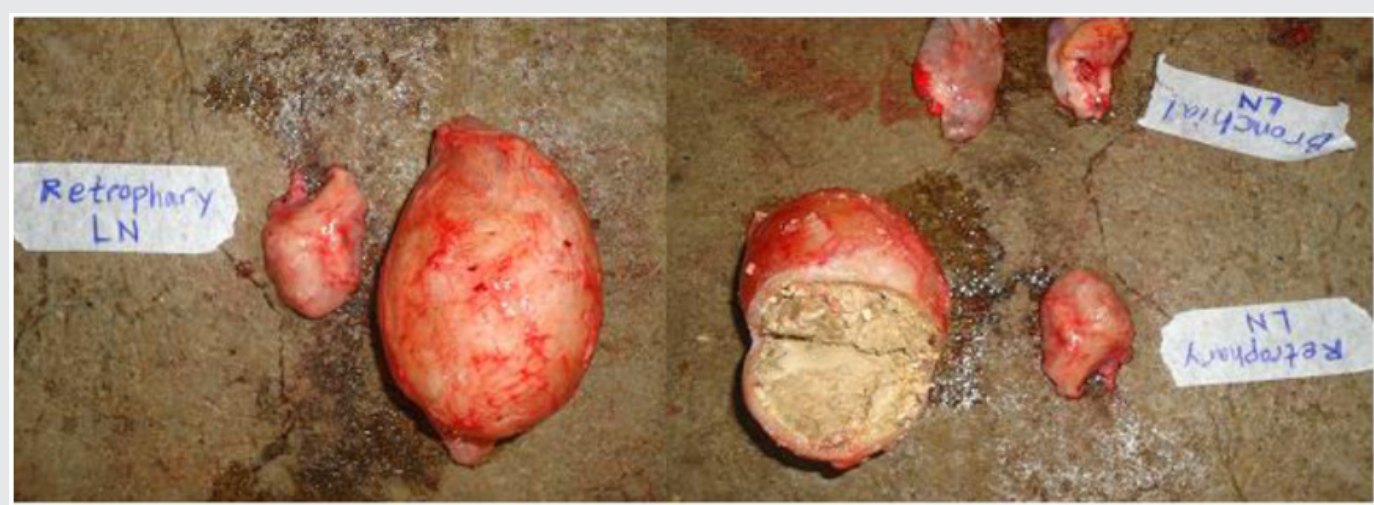

Figure 3: Enlarged and mass of calcified retrophayngeal lymph node of investigated camel. 
Pathology scoring for the severity of gross lesions was undertaken on tissues with abscesses and tubercle lesions to determine the severity of the lesions based on semi quantitative procedure developed by $[24,25]$ and adopted for camel tuberculosis lesion scoring. Briefly, lesions in the lung scored separately as follows: 0 , no visible lesions; 1 , no gross lesions but lesions apparent on slicing of the lung lobe; 2 , fewer than five gross lesions; 3 , more than five gross lesions; 4 , gross coalescing lesions. The scores of the individual lobes were added up to calculate the lung score. Similarly, the severity of gross lesions in individual lymph nodes was scored as follows: 0 , no visible lesions; 1 , a small lesion at one focus (just starting); 2 , small lesions at more than one focus; 3 , extensive necrosis. Individual lymph node scores were added up to calculate the lymph node score. Finally, both lymph node and lung pathology scores were added up to determine the total pathology score per camel.

\section{Data Analysis}

Data were entered into Microsoft excel sheet, coded and analyzed using statistical packages: STATA (Intercooled Stata version 13) and SPSS (version 20). Descriptive statistics were used to estimate lesion prevalence and the mean severity of pathology scoring. Pearson chi-square test was used to assess the association of risk factors of age, sex, origin, and body condition of camels with lesion prevalence. The multivariable logistic regression analysis, the odds ratio (95\% confidence interval) was used to assess the strength of association of these risk factors with the prevalence. For statistical significance, 95\% confidence level and P-value of 0.05 were considered.

\section{Results}

Of the total 2070 camels investigated during post mortem examination, 156 camels were detected with gross tuberculosis lesion with lesion prevalence of 7.54\% (95\% CI: 6.45\% - 8.7\%). During the study, most camels were with poor body condition, of Borena origin, old aged, and unproductive female camels. Among investigated camels, 81.74\% (1692/2070) were old age ( $>7$ years of age) and $18.3 \%(378 / 2070)$ were adult camels ( $\leq 7$ years of age); $83.7 \%$ were female camels and $16.33 \%$ were males. Higher lesion prevalence of $7.74 \%(131 / 1692)$ was detected in older camels ( $>7$ years) than adult camels ( $\leq 7$ years) with lesion prevalence of $6.61 \%$. Statistically significant association $(\mathrm{P}=0.000, \chi 2=26.2)$ was observed between body condition and prevalence with lesion prevalence of $12.1 \%, 6.7 \%$, and $5.2 \%$ in poor, moderate, and good body conditions, respectively. However, there was no statistically significant association $(\mathrm{P}>0.05)$ was observed between risk factors of age, sex, and origin of camels with lesion prevalence (Table 1).

Table 1: The Pearson Chi-square test for the association of risk factors with lesion prevalence.

\begin{tabular}{|c|c|c|c|c|}
\hline Variables & No. Examined (\%) & No. Positive (\%) & $\chi^{2}$ & P-value \\
\hline \multicolumn{5}{|c|}{ Age } \\
\hline$\leq 7$ years & $378(18.3)$ & $25(6.61)$ & \multirow{2}{*}{0.5647} & \multirow{2}{*}{0.452} \\
\hline$>7$ years & $1692(81.74)$ & $131(7.74)$ & & \\
\hline \multicolumn{5}{|c|}{ Sex } \\
\hline Male & $338(16.33)$ & $20(5.9)$ & \multirow{2}{*}{1.52} & \multirow{2}{*}{0.218} \\
\hline Female & $1732(83.7)$ & $136(7.9)$ & & \\
\hline \multicolumn{5}{|c|}{ Body Cond. } \\
\hline Poor & $594(28.7)$ & $72(12.1)$ & \multirow{3}{*}{26.2} & \multirow{3}{*}{$0.000^{*}$} \\
\hline Moderate & $510(24.64)$ & $34(6.7)$ & & \\
\hline Good & $966(46.7)$ & $50(5.2)$ & & \\
\hline \multicolumn{5}{|c|}{ Origin } \\
\hline Borena & $1739(84)$ & $131(7.53)$ & \multirow{2}{*}{0.002} & \multirow{2}{*}{0.99} \\
\hline Metehara & $331(16)$ & $25(7.6)$ & & \\
\hline
\end{tabular}

The multivariable logistic regression analysis revealed that being poor body conditioned was found to be associated risk factor for the detection of gross tubercle lesions and significantly associated $(\mathrm{P}=0.000)$ with lesion prevalence of tuberculosis in camels [Adjusted OR= 2.55 (95\% CI: 1.743-3.734)] (Table 2). The frequency of severity of lesion (pathology score of the lymph nodes) showed, $73.7 \%$ of the lesions of camels were with pathology score of $1,16.03 \%$ with score of 2 , and $10.9 \%$ with severe lesion (score of 3). Frequency of lesion distribution showed, $84 \%$ of the lesions were detected in older camels $>7$ years, whereas $16 \%$ in adult camels of $\leq 7$ years of age. Moreover, higher frequency of lesion with $87.2 \%, 46.2 \%$, and $84 \%$ were recorded in female, poor conditioned, and Borena origin camels, respectively. Pathology score for severity of gross lesions in terms of age, sex, body condition and origin of camels were also indicated in the table below (Table 3).

Table 2: Multivariable logistic regression for association of risk factors with lesion prevalence.

\begin{tabular}{|c|c|c|c|c|}
\hline \multicolumn{2}{|c|}{ Variables } & No. Examined (\%) & No. Positive (\%) & A0R (95\% CI) \\
\hline \multicolumn{3}{|c|}{ Age (95\% CI) } & $25(6.61)$ & 1 \\
$>7$ years & $378(18.3)$ & $131(7.74)$ & $1.185(0.761-1.846)$ \\
\hline
\end{tabular}




\begin{tabular}{|c|c|c|c|c|}
\hline \multicolumn{5}{|c|}{ Sex } \\
\hline Male & 338 (16.33) & $20(5.9)$ & 1 & 1 \\
\hline Female & $1732(83.7)$ & $136(7.9)$ & $1.355(0.835-2.1996)$ & $1.189(0.726-1.946)$ \\
\hline \multicolumn{5}{|c|}{ Body Cond. } \\
\hline Poor & 594 (28.7) & $72(12.1)$ & $2.527(1.734-3.682)$ & $2.55(1.743-3.734)$ \\
\hline Moderate & $510(24.64)$ & $34(6.7)$ & $1.309(0.835-2.0512)$ & $1.312(0.835-2.061)$ \\
\hline Good & $966(46.7)$ & $50(5.2)$ & 1 & 1 \\
\hline \multicolumn{5}{|c|}{ Origin } \\
\hline \multirow{2}{*}{ Borena Metehara } & $1739(84)$ & $131(7.53)$ & $0.9972(0.6391-1.556)$ & $1.071(0.6814-1.683)$ \\
\hline & $331(16)$ & $25(7.6)$ & 1 & 1 \\
\hline
\end{tabular}

Table 3: Pathology score for severity of typical tubercle lesions in terms of host risk factors.

\begin{tabular}{|c|c|c|c|c|}
\hline \multirow{2}{*}{ Variables } & \multirow{2}{*}{ No. Lesion (\%) } & \multicolumn{3}{|c|}{ Pathology Score (\%) } \\
\hline & & 1 & 2 & 3 \\
\hline \multicolumn{5}{|c|}{ Age } \\
\hline$\leq 7$ years & $25(16)$ & $20(17.4)$ & $4(16)$ & $1(5.9)$ \\
\hline$>7$ years & $131(84)$ & $95(82.6)$ & $21(84)$ & $16(94.1)$ \\
\hline \multicolumn{5}{|c|}{ Sex } \\
\hline Male & $20(12.8)$ & $19(16.5)$ & $1(4)$ & $1(5.9)$ \\
\hline Female & $136(87.2)$ & $96(83.5)$ & $24(96)$ & $16(94.1)$ \\
\hline \multicolumn{5}{|c|}{ Body Cond. } \\
\hline Poor & $72(46.2)$ & $53(46.1)$ & $11(44)$ & $8(47.1)$ \\
\hline Moderate & $34(21.8)$ & $24(20.9)$ & $5(20)$ & $6(35.3)$ \\
\hline Good & $50(32.1)$ & $38(33.0)$ & $9(36)$ & $3(17.6)$ \\
\hline \multicolumn{5}{|c|}{ Origin } \\
\hline Borena & $131(84)$ & $101(87.8)$ & $19(76)$ & $12(70.6)$ \\
\hline Metehara & $25(16)$ & $14(12.2)$ & $6(24)$ & $5(29.4)$ \\
\hline Total & $156(7.54)$ & 115 (73.7) & 25 (16.03) & $17(10.9)$ \\
\hline
\end{tabular}

Of the 156 camels detected with gross visible lesions, the score for severity of lesions of lung tissue, lung associated lymph distribution, frequency, and severity of the lesions were assessed. Thus, the distribution and frequency of the lesions were high in sub-mandulbular lymph node (SMLN) (54.8\%), followed by retropharyngeal lymph nodes (RPLN) (16.94\%), trachea- broncheal lymph nodes (TrBLN) (10.73\%), parotid lymph node (PLN) (7.34\%), lung (6.2\%), and the least frequency being detected in caudal mediastinal lymph node (CaMLN) (2.82\%) and cranial mediastinal lymph node (CrMLN) (1.13\%) (Figure 4). Pathology nodes and lymph nodes of the head showed, severe lesions was detected in sub-mandibular lymph node more frequently than the other lymph nodes with the mean severity of $2.47 \pm 0.24$, followed by retro-pharyngeal $(0.35 \pm 0.19)$ and caudal mediastinal lymph nodes $(0.35 \pm 0.19)$ (Table 4$)$. Of the total 156 camels detected with gross typical tuberculosis lesions, 92.9\% (145/156) exhibited at least one lesion in their tissues while 7.1\% (11/156) showed more than one lesion in their tissues.

Table 4: Pathology score for severity of tubercle lesions from different tissues of camels.

\begin{tabular}{|c|c|c|c|c|}
\hline \multirow{2}{*}{ No. } & \multirow{2}{*}{ Tissues examined } & \multicolumn{3}{|c|}{ Mean \pm SE of Pathology Score } \\
\cline { 3 - 5 } & & $\mathbf{1}$ & $\mathbf{2}$ & $\mathbf{3}$ \\
\hline 1 & CrMLN & $0.01 \pm 0.009$ & $0.08 \pm 0.08$ & - \\
\hline 2 & CaMLN & $0.01 \pm 0.009$ & $0.00 \pm 0.00$ & $0.35 \pm 0.19$ \\
\hline 3 & SMLN & $0.57 \pm 0.05$ & $1.12 \pm 0.19$ & $0.47 \pm 0.24$ \\
\hline 4 & RPLN & $0.17 \pm 0.035$ & $0.40 \pm 0.14$ & $0.35 \pm 0.19$ \\
\hline 5 & TrBLN & $0.07 \pm 0.024$ & $0.40 \pm 0.14$ & - \\
\hline 6 & PLN & $0.11 \pm 0.03$ & - & - \\
\hline
\end{tabular}




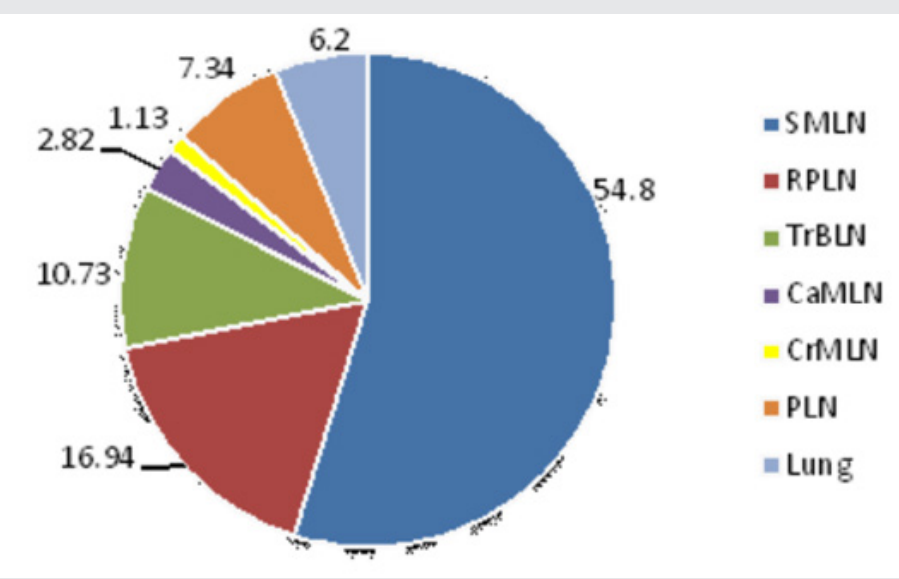

Figure 4: Frequency and lesion distribution in lung and lymph node tissues.

\section{Discussion}

Information regarding the occurrence and epidemiology of Tuberculosis in camels is very scarce in Ethiopia and many other camel rearing countries in the world. In this abattoir based epidemiological investigation, detection of gross pathology typical for tubercle lesion with the overall lesion prevalence of $7.54 \%$ was recorded. This finding is slightly lower than from the reports of [9] for camels in Eastern Ethiopia and [8] for camels at Kazakistan; but it was slightly higher than the finding of [15] for camels at Eastern and Southern Ethiopia; Again, the current finding was higher than from previous reports of [26] for camels at Cairo abattoir and the work of [10] for camels in Pakistan. The current finding was lower than from that of [27] for camels in Eastern Ethiopia. However, the present finding was higher than previous reports of [14] for camels slaughtered at Akaki abattoir and [28] for camels which were kept in close contact with cattle in Egypt, and also from that of [8] in camels at Kazakistan. This variation might be due to difference in geographic location, husbandry practice, study design, predisposition of host species might all be factors for lesion prevalence variations.

During the study, $81.74 \%$ of the camels were old aged ( $>7$ years) and $18.3 \%$ were adult ( $\leq 7$ years) camels. Lesion detection rate was higher in older camels with lesion prevalence of $7.74 \%$ than adult camels $(6.61 \%)$. In the current study, the association of age as a risk factor with lesion prevalence of tuberculosis in camels was not statistically significant $(\mathrm{P}>0.05)$ and this finding was in agreement with previous works by different authors [9,14] for camels. [9] reported in his study that the frequency of lesion detection was higher in older than younger camels. Other researchers have also reported in cattle that older animals are affected by TB [29-32] which could be due to the fact that older animals have weaker immune system and might have higher rate of exposure to infection in the course of the longer life span. This fact can be substantiated by the chronic nature of the disease tuberculosis in which case the animals might have acquired the infection at younger age and developed the disease at an older age [7].

Regarding sex, about $83.7 \%$, and $16.3 \%$ of the study camels were unproductive female and male camels, with lesion prevalence of $7.9 \%$ and $5.9 \%$ were detected in female and male camels, respectively. The present finding was consistent with previous studies of some authors $[9,14]$ for camels. Similarly, as [9] reported that lesion was more frequently observed in female camels as compared to male camels. This could be due to the fact that female camels were brought for slaughter at their older age after completion of their productive and reproductive age as it is substantiated by some authors [30,33]. Poor body conditioned camels revealed significantly higher lesion prevalence (12.1\%) than the lesion prevalence of $6.7 \%$ and $5.18 \%$ in moderate and good body conditioned camels, respectively. The high prevalence reported in poor conditioned camels in this study was in agreement with previous reports of $[14,15]$. Poor conditioned animals are nutritionally and immunologically compromised to defend and combat infectious agents. It was also consistent with previous reports which indicated that animals with poor body condition have relatively low resistance to infectious agents [7].

There was no difference in the lesion prevalence recorded for Borena and Metahra origin camels. This finding is consistent and comparable with previous works [14,15]. However, [14] reported higher lesion prevalence in Metehara origin camels than Borena camels. Majority of the camels investigated during this study were Borena origin camels (84\%) with very few of Metehara origin camels (16\%). This uncomparable number of camels of Borena and Metehara origin slaughtered during the investigation might have influenced the appreciation of origin of the camels as a risk factor of tuberculosis where the lesion prevalence was almost similar. Moreover, environmental factors, husbandry and management practices where these camels brought from, might have influenced the status and frequency of the disease.

The distribution, frequency, and severity of gross tuberculosis lesions were found to be high in sub- mandibular lymph node (54.8\%) followed by retropharyngeal lymph node $(16.95 \%)$ and trachea- broncheal lymph node (10.7\%). This might indicate the predominant portal route of entry of mycobacterial agents in camels might be by inhalation. Although not investigated in detail during this study, the presence of TB lesions in mesenteric lymph nodes also indicates the existence of infection through ingestion [7]. Similar studies of some other researchers revealed slight variation in the frequency, distribution and severity of gross visible lesions detected in different tissues. Previous reports of [34] showed lesions were predominantly detected more frequently in 
mediastinal lymph node followed by retropharyngeal lymph node; [14] also indicated that more frequent lesion being detected in the right cardiac lung and cranial mediastinal lymph node; whereas, [9] reported that severe and more frequent tuberculous lesions in mesenteric lymph node and mediastinal lymph node. Reports from developed countries indicated that tuberculosis lesions are found most frequently in the lymphatic tissues of the thoracic cavity.

In intensive husbandry system, $90 \%$ of the lesions occur in the respiratory tract $[5,35]$. The report by [36] showed that $94.5 \%$ of the lesions were detected in mesenteric lymph nodes in animals that kept on pasture. [36] also mentioned that all cases of Tuberculosis in OWCs had lesions at the lungs and associated thoracic lymph nodes, where typical caseo-necrotic lesions can be particularly extensive. Ethiopian studies have described $54 \%$ of infected OWCs with lesions in the lung and associated lymph nodes, and $38 \%$ with mesenteric lymph node lesions, followed by retropharyngeal lymph node involvement [15]. Of the total 156 camels with tuberculosis lesion, 7.1\% (11 camels) were with more than one lesion in different lymph nodes and the remaining 92.9\% (145 camels) with at least one lesion in their lymph node tissues. The severity of tuberculosis lesions showed $9.04 \%$ of the tissue lesions were with severe pathology (score of 3 ) and $78.5 \%$ of tissues with mild pathology of score 1 .

Comparable finding was previously reported by $[9,23]$ indicated that the detection of severe lesions was more frequent in mesenteric lymph node followed by mediastinal lymph node in camels. The current finding revealed that tuberculosis lesions were extensive in slaughtered camels of Borena and Metehara origin at Akaki abattoir, although in general, camels seem to be resistant against a number of diseases affecting other animal species. Tuberculosis is an existing phenomenon in camels and the findings in this study had revealed that tuberculosis in camel could occur and affect health and production of camel in pastoralist areas with potential public health concern, since pastoralists share the same environment (confinement) with their animals and the consumption of raw or unpasteurized milk and milk products in pastoralist communities is common practice.

\section{Conclusion}

In this study extensive tuberculosis lesion was detected more frequently from sub-mandibular lymph node, retropharyngeal lymph node and trachea-broncheal lymph node. It was suggested that tuberculosis evidently common and prevalent in camels. However, the present study can be complimented by cultural isolation and molecular characterization of circulating strains of tuberculosis causing agents in camels. The possibility of potential role of camels in the epidemiology of tuberculosis in humans in pastoralist area including the transmission dynamics warrants further epidemiological investigations.

\section{Declarations}

\section{Ethics Approval and Consent to Participate}

Not applicable: Since it is abattoir based study, camels meant for slaughtering were examined and their tissues were sampled for gross pathological examination and scoring.

\section{Consent for Publication}

Not applicable.

\section{Availability of Data and Materials}

The datasets used and analyzed during the current study are available from the corresponding author on reasonable request.

\section{Competing Interests}

The authors declare that they have no competing interests.

\section{Funding}

This study was funded by the Thematic Research Program of Addis Ababa University.

\section{Authors' Contributions}

YJ was involved in the design, data collection, analysis and interpretation of data and drafted the paper; GM was involved in the design, supervision of data collection and analysis, and critical revision; JA and GM involved in post mortem examination, $\mathrm{AI}$ involved in data analysis and critical revision of the paper, and GA was involved in the design, supervision, data analysis and critical revision of the paper. All authors have read and approved the paper for submission.

\section{Acknowledgement}

Authors would like to acknowledge the full cooperation of Addis Ababa Abattoirs enterprise for allowing us to conduct post mortem examination on camels slaughtered at its Akaki branch camel slaughter house. The financial and material support of Aklilu Lemma Institute of Patho-biology of Addis Ababa University through Thematic Research Program is highly acknowledged.

\section{References}

1. Markakis J (2004) Pastoralism on the margin. Report Minority Rights Group International p. 15.

2. Nori M (2005) Sustainable camel milk production and commercialization in Somalia. Future Livestock Systems APS course, Wageningen-4.

3. Rhodes S, Crawshaw T, DelaRea Demenech R, Bradford S, Lyashchenko KP (2015) Mycobacterial Infections in Camelids. Tuberculosis, Leprosy and Mycobacterial Diseases of Man and Animals pp. 216-234.

4. Mustafa IE (2013) Bacterial diseases of dromedaries and bacterian camels. Rev Sci tech Off Int Epiz 6(2): 391-405.

5. Neill SD, Cassidy J, Hanna J, Mackie DP, Pollock JA, et al. (1994) Detection of Mycobacterium bovis infection in skin test-negative cattle with an assay for bovine interferon- gamma. Vet Rec 135(6): 134-135.

6. (2012) Oromiya Pastoralist Areas Development Commision (OPADC) Camel Development road map, Oromiya National Regional State, Draft document, Zeway.

7. Radostits OM, Gay CC, Blood DC, Hinchclif KW (2007) Veterinary medicine. A text book of the disease of cattle, sheep, pigs, goats and horses. 10th (edn.). London Saunder Elsevier p. 471-500.

8. Elmossalami E, Siam MA, El Sergany M (1971) Studies on tuberculosislike lesions in slaughtered camels. Zentralbl Veterinarmed B 18(4): 253261.

9. Mamo G, Bayleyegn G, Sisay T, Legesse M, Medhin G, et al. (2011) Pathology of Camel Tuberculosis and Molecular Characterization of its Causative Agents in Patoral Regions of Ethiopia. PLoS ONE, A peerReviewed Open Access Journal 6(1): 1-10. 
10. Zubair R, Khan AMZ, Sabri MA (2004) Pathology in camel lungs. J camel science 1: 103-106.

11. Abubakar UB, Kudi AC, Abdulkadir IA, Okaiyeto SO (2014) Prevalence of tuberculosis in slaughtered camels (Camelus dromedaries) at Kano abattoir, Nigeria, based on lateral flow technology. Journal of Camel Practice and Research 21(1): 41-45.

12. Beye AF, Zerom KG, Mussa A, Ameni G, Sanni MA (2014) Prevalence of bovine tuberculosis in dromedary camels and awareness of pastoralists about its zoonotic importance in Eastern Ethiopia. Journal of Veterinary Medicine and Animal Health 6(4): 109-115.

13. Gumi B, Schelling E, Erenso G, Firdessa R, Biffa D, et al. (2012) Low Prevalence of bovine tuberculosis in Somali pastoral livestock, Southeast Ethiopia. Trop Anim Health Prod 44(7): 1445-1450.

14. Kassaye S, Molla W, Ameni G (2013) Prevalence of Camel Tuberculosis at Akaki abattoir in Addis Ababa, Ethiopia. African Journal of Microbiology Research 7(20): 2184-2189.

15. Mamo G, Kassaye A, Sanni M, Ameni G (2009) A cross sectional study of Camel Tuberculosis in Ethiopia. Bull Anim Hlth Prod Afr 57(1): 13-20.

16. Zerom K, Sisay T, Mamo G, Bayu Y, Ameni G (2013) Tuberculosis in dromedaries in Eastern Ethiopia: Abattoir-based prevalence and molecular typing of its causative agents in camels. Research J 109: 188192.

17. (2008) CSA. Federal Democratic Republic of Ethiopia, Central Statistical Agency. Agricultural Sample Survey Report on Livestock and Livestock Characteristics, Addis Ababa, Statistical bull 2: 16

18. (2012) Central Australian Camel Industry Association Inc (CACIA).

19. Schwartz HJ, Dioli M (1992) The one humped camel in eastern Africa. Apictorial guide to disease, Health care and management. Weikeersheini, Verlagiosef monograph p. 1-59.

20. Thrusfield M (2007) Veterinary Epidemiology. $3^{\text {rd }}$ (edn.). Oxford, UK: Blackwell Science Ltd, a Blackwell publishing company pp. 228-242.

21. Corner LA (1994) Post mortem diagnosis of Mycobacterium bovis infection in cattle. Vet Microbiol 40(1-2): 53-63.

22. Bogale B, Woldesenbet Z, Yimer E, Lemma E (2004) Evaluation of abattoir inspection for the diagnosis of Mycobacterium bovis infection in cattle at Addis Ababa abattoir. Trop Anim Health Prod 36(6): 537-546.

23. Kinne J, Johnson B, Jahans KL, Smith NH, Ul Haq A, et al. (2006) Camel Tuberculosis-a case report. Trop Anim Health Prod 38(3): 207-213.

24. Ameni G, Aseffa A, Engers H, Young D, Hewinson G, et al. (2006) Cattle husbandry in Ethiopia is a predominant factor affecting the pathology of bovine tuberculosis and gamma interferon responses to mycobacterial antigens. Clin Vaccine Immunol 13(9): 1030-1036.

ISSN: 2574-1241

DOI: 10.26717/BJSTR.2019.19.003263

Yasmin Jibril. Biomed J Sci \& Tech Res

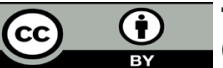

This work is licensed under Creative

Commons Attribution 4.0 License

Submission Link: https://biomedres.us/submit-manuscript.php
25. Vordermeier HM, Chambers MA, Cockle PJ, Whelan AO, Simmons J, et al. (2002) Correlation of ESAT-6- Specific Gamma Interferon with Pathology in Cattle Following Mycobacterium bovis BCG Vaccination against Experimental Bovine Tuberculosis. Infect Immunol 70(6): 30263032 .

26. Mason FE (1917) Tuberculosis in camels. J comp Path Therap 30: 80-84.

27. Manal MY, Gobran RA (2008) Some studies on Tuberculosis in Camel. Egypt J Comp Path and Clinic Path 21(4): 58-74.

28. Cleaveland S, Shaw DJ, Mfinanga SG, Shirima G, Kazwala RR, et al. (2007) Mycobacterium bovis in rural Tanzania: Risk Factors for Infection in Human and Cattle Populations. Tuberculosis 87(1): 30-43.

29. Inangolet FO, Biffa D, Oloya J, Opuda Asibo J, Skjerve E (2008) A CrossSectional Study of Bovine Tuberculosis in the Transhumant and AgroPastoral Cattle Herds in the Border Areas of Katakwi and Moroto Districts, Uganda. Trop Anim Hlth Prod 40(7): 501-508.

30. Kazwala RR, Kambarage DM, Daborn CJ, Nyange J, Jiwa SF, et al. (2001) Risk factors associated with the occurrence of bovine tuberculosis in cattle in the Southern Highlands of Tanzania. Vet Res Commun 25(8): 609-614.

31. Munyeme M, Muma JB, Samui KL, Skjerve E, Nambota AM, et al. (2008) Prevalence of bovine tuberculosis and animal level risk factors for indigenous cattle under different grazing strategies in the livestock/ wildlife interface areas of Zambia. Trop Anim Health Prod 41(3): 345352 .

32. Munyeme M, Muma JB, Skjerve E, Nambota AM, Phiri IG, et al. (2008) Risk Factors Associated with Bovine Tuberculosis in Traditional Cattle of the Livestock/Wildlife Interface Areas in the Kafue Basin of Zambia. Prev Vet Med 85(3-4): 317-328.

33. Tsegaye W, Aseffa A, Mache A, Mengistu Y, Berg S, et al. (2010) Conventional and Molecular Epidemiology of Bovine Tuberculosis in Dairy Farms in Addis Ababa City, the Capital of Ethiopia. Intern J Appl Res Vet Med 8(2): 143-151.

34. Corner LA, Melville L, McCubbin K, Small KJ, McCormick BS, et al. (1990) Efficiency of inspection procedures for detection of tuberculous lesions in cattle. Aust Vet J 67(11): 389-392.

35. Ameni G, Aseffa A, Engers H, Young D, Gordon S, et al. (2007) High prevalence and increased severity of pathology of bovine tuberculosis in Holsteins compared to zebu breeds under field cattle husbandry in central Ethiopia. Clin Vaccine Immunol 14(10): 1356-1361.

36. Mason FE (1912) Some observations on tuberculosis in camels in Egypt. J comp Path Therap 25: 109-111.

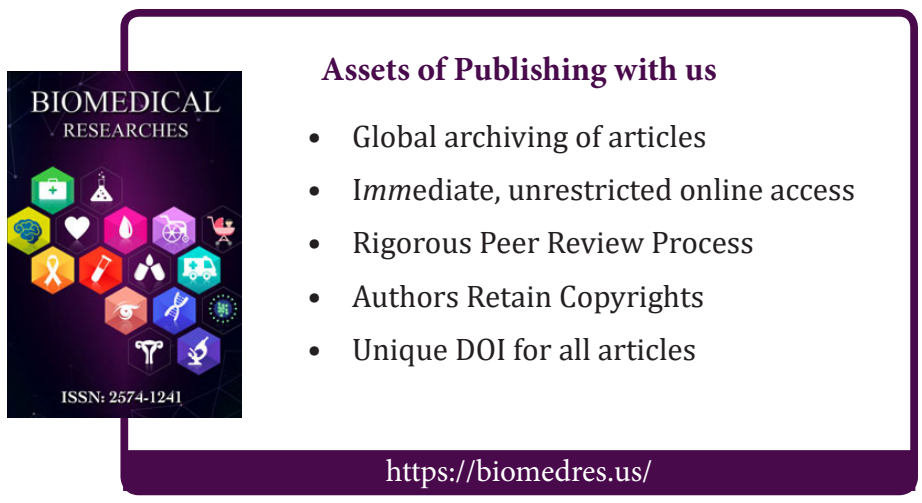

Copyright@ Yasmin Jibril | Biomed J Sci \& Tech Res | BJSTR. MS.ID.003263. 